\title{
Obstacles of E-Learning in the Jordanian Secondary Schools from the Perspective of the Teachers in Amman Fifth Directorate of Education
}

\author{
Malloh Mfadi Bartakat Sleihat ${ }^{1, *} \&$ Madher M. Attiat ${ }^{2}$ \\ ${ }^{1}$ Department of Basic Science, Princess Rahma University College, Balqa Applied \\ University, Al-Salt, Jordan \\ ${ }^{2}$ Educational Psychology (Measurement and Evaluation), Princess Rahma University \\ College, Balqa Applied University, Al-Salt, Jordan \\ *Corresponding author: Department of Basic Science, Princess Rahma University College, \\ Balqa Applied University, Al-Salt, Jordan. E-mail: mallouh_abadi@yahoo.com
}

Received: May 19, 2013 Accepted: August 5, 2013 Published: October 17, 2013

doi:10.5296/ije.v5i4.3720 URL: http://dx.doi.org/10.5296/ije.v5i4.3720

\begin{abstract}
This study aimed to reveal the obstacles in using e-learning in the curriculum of the Jordanian ministry of education on the electronic website of the ministry from the teachers of secondary level through answering the following two questions:

1. What are the obstacles of e-learning in the Ministry of education in Jordan from the perspective of the teachers of the secondary level?

2. Are there significant differences at the level of significant $(a=0.05)$ attributed the variables; sex, specialization and experience?

And to achieve the objectives of the study, a random sample consisted of 201 teachers of the secondary level was selected and a questionnaire which consisted of 30 items was developed and its validity and reliability were achieved. The results of the study indicated that the field of technical and administrative came in first rank with a moderated level while the field of obstacles regarding the teacher came in the second rank with a moderate level. And the technical and the administrative obstacles varied according to variables: sex, specialization in favor to the females and the scientific subjects respectively whereas there was no significance to the experience variable. So based on these results, the study recommended the necessity of overcoming the obstacles facing e-learning which this study and others revealed and working on developing the infrastructure that supported using e-learning.
\end{abstract}

Keywords: e-learning; education; secondary schools 


\section{Introduction \& Theoretical Background}

The scientific, informatics and technological revolution has produced many educational, cultural, scientific, political and economic challenges. And because of these challenges, there was a need to reform the educational system within its inputs, operations and outcomes to face these challenges so it was obligatory for the educational system to pay much attention to its human inputs and prepare them to be qualified to use the computer.

And the computers have played an important role in education sector; they are used in all the levels of education starting from preparing and implementing the lessons till preparing the exams, evaluating the students and analyzing their results. The World Wide Web is considered one of the basic component in the field of education in all its different levels. And the number of the schools which use the computers and Internet in the processes of teaching and learning increases. And, this use is not any more considered a luxury, but it becomes a necessity imposed by the technological developments, which become able to reform the education's system and its institutions of what it presents of new teaching and learning strategies, evaluation, presenting knowledge and new methods in the educational system's administration (Khan, 2005).

The educational system invested this development and progress by establishing an integrated learning system, that depends on this technology, known by Electronic learning which becomes a necessity to provide the learners with the required skills of the future .E-learning is considered one of the modern attitudes of education's system and many terms are used to refer to the e-learning as: Online Learning, (Electronic Education), Virtual Learning and (Web Based Learning) (Salem, 2006).

The researches do not agree on a specific definition of e-learning especially with the existence of other terms that have overlapping in between as distance learning, Open learning, Virtual Learning and Flexible learning. Mosa \& Mobarak(2005) defined e-learning as a method of learning using modern communication mechanisms as sound, image, search engines, e-libraries, Internet either this was inside the classroom or online. And Khan (2005)defined e-learning as a creative method used to present an interactive environment which is learners' centered, designed well and easy to be used for learning to any one , in anytime and in anywhere by using internet resources that commensurate with the learning environment. And this was asserted by (Anderson, 2004) when he considered e-learning the use of multimedia to improve the process of learning and to facilitate the access into the information. And Rashed added (2003) that e-learning is not an alternative to the teacher but it enhances his role as a supervisor, a guide and an organizer of the educational process which make it compatible with the development of technology. And both of Mheisn(2003) \&Bosman(2002) agreed that e-learning is the education which depends on using the electronic media in the communications between the learners, the teacher and the educational institution.

E-learning aims to activate and employ the latest technology to access into effective learning that follows up the innovative technologies and communication s to develop the process of learning and teaching. And rapid increase of interest of this kind of education forced many 
countries as USA, Canada and UK to compete in starting projects of e -learning and allocate budget to fund these e-learning projects, similarly, the developing countries started to use technology in the process of learning. For its advantages and benefits that help learners in using technology and communication in the processes of teaching and learning (Azmi, 2008).

Based on the vision of King Abdallah Bin Al-Hussein which he expresses by saying: "Jordan will become a center of information technology in the region", Ministry of Education with the help of Canada put a strategic plan to apply the initiative of e-learning and soak to develop tools and means of information technology and communications starting by providing infrastructure through providing and preparing the computer labs till developing the content of e-learning and organizing many training workshops. And the Ministry of Education has developed a common vision to the future of education in Jordan and adopted a national strategy of e-learning which is based on employing the modern technology to transfer economy of knowledge where the knowledge and the means that support its achievement and keeping it is the basic of the educational system in Jordan(Fayumi,2004).

To apply the initiative of e-learning, Ministry of Education established many projects and e-libraries, centers of information technology and electronic gates. One of these projects is the exploratory schools which aimed to supply the teachers with the technology needed to the classroom; to provide the educational material to the learners through giving a laptop to every teacher and through the computer labs, computerizing the curriculum, and providing electronic training to the teachers and the administrators. And in 12001, the ministry established a unit to coordinate the e-learning; to lead the process of change in the ministry, to plan for the strategy of the e-learning, to provide facilities so as to guarantee the process of implementation and to prepare the remedies plans for the central application of e-learning. And the ministry developed an educational system to support e-learning called Eduwave which was developed to include levels of the higher education and the basic one. And the Center of Queen Rania of Information Technology is considered as an electronic gate aims at using modern technology to serve education and develop it in Jordan. this center links more than 1500 schools with the directorates and the centers of learning resources by an internal network(Intranet)and this center is used as the major base to link the school through the project of e-learning (Ministry of Education,2004).

And to provide the proper atmosphere of e-learning, planning and previous preparation should be done in terms of choosing the appropriate technicians of the scientific content of the material, accuracy in following up and evaluation which is considered one of the most important requirements of e-learning in addition to provide the infrastructure of computers and networks and to have the curriculum of the computer as a basic curriculum in all of the levels of education, to encourage the institutions and the individuals to produce educational programs via modern technicians, to provide people who are qualified and capable to follow up working on the system and to provide the necessary maintenance. It is also necessary to have the community's awareness towards the importance of this kind of learning starting for the decision makers to the ordinary citizen (Torky, 2003).

Zajda and Gibbs(2009) believe that there are four element help in succeeding the experiment 
of e-learning in schools as: first: the good design of the network or the project of the e-learning which will contribute in forming educational experiences through a number of activities which the design has and can used inside the classroom. Second: the existence of sufficient support and control to the process of learning, because the students still need their teachers' guidance and orientation. And this guidance enable the teachers to identify the learning patterns of their students and the problems they face. Third: the ability to use all the available means and this element indicates to the teacher's experience in the interaction and the communication with different programs and learning resources that support the processes of learning and teaching. The teachers need to have new skills in using e-learning to facilitate the process of learning and teaching in the environment of e-learning.

And e-learning requires having systems to administer the learning and the education which provide the communication between all the parts of the educational process . These systems aimed to raise the efficiency of e-learning by the availability of the following: basic infrastructure, distributed electronic content, different interactive levels, variety of relations between the teacher, the learner, the manager and the parents and evaluation and different exams. And to have this system under the Officials' control, there should be an electronic system that helps in coordinating and administering the system to have the integration between its components in term of admission, registration, electronic curriculum, evaluation and the exams. And managing learning is considered the most important component of e-learning because it is responsible for managing the electronic educational process through the local network of information(Talba,2007).

There are many international systems which were produced to manage e-learning and they are divided into two major parts: the first one: systems of managing e-learning with resource -open. They are the systems which are used freely and they are not for sale and they could be modified and developed continuously. The second one: systems of administering e-learning with closed-source or the commercial. And they are the systems owned by profitable firms and they are developed continuously and it does not allow anyone to use them without authorization. And these systems are characterized of providing a forum to discuss the issues suggested by the teacher and the learner. And they allow the users the opportunity to use e-mail and the possibility to search for the available curriculum and establish exams with their forms according to the standards which the teachers suggested (Harris, Mishra \& Koehler, 2009) .

The system of e-learning (Eduwave) which the Ministry of Education in Jordan adopted is considered as one of the close - source e-learning system that aimed to improve and develop the process of learning and teaching to improve the outcomes of the educational process and to move towards a vital learning resulted of discovery, research, analyze, problem solving through using technology and means of communications and the computerized curriculum, and the integration of technology to get more benefits(Ministry of Education, 2012).

E-learning provides a new culture that could be named by the digital culture and it is different from the traditional culture or from what is known by the printed culture. In the time that the digital culture focused on processing the knowledge and the learner is the center of this 
culture, the printed culture focused on producing the knowledge where the teacher is the center of the traditional methods of teaching. e-learning helps providing opportunities to the different categories of the community and in any time and according the learner's capabilities in the achievement and understanding, and e-learning contributes in developing thinking, enriching the process of learning and helping the learner to depend on himself and giving him the freedom to express himself comparing with the traditional education. And the student gets a continues feed back during the process of learning for what this kind of learning provides as self and final evaluation. And e-learning is characterized of ability to update easily the websites and the educational programs and to modify the information and the subjected presented in, the speed of transmitting information depending on internet and it provides the possibility of communication to exchange ideas and experiences from the learners' perspective via e-mail, interactive video and discussion rooms (Rashed,2003).

And because e-leaning is based on the individual's participation in the activities of education, there is the desire to learn; the learner acquires the way of learning in one hand which means long life learning and the leaner will have motivation and positive attitudes towards the process of learning on the other hand and thus learner will be able to develop himself. So in this era, e-learning is considered as the best available way for the continuous learning that helps the individual to long life learning (Khan, 2005)

And there are other obstacles that hinder e-learning from achieving its objectives and the technological challenges are considered the most challenges which Jordan have faced in the field of e-learning. These challenges are represented by the ministry's limitation in establishing wide networks, providing a big number of computers and tools because of the difficulty of allocating the necessary finance to construct the infrastructure which is represented by providing the computers and their accessories, facilitating the communication, providing the necessary and the continuous maintenance to the machines and to the net of the communication, the challenge of the difficulty of communication with internet and its high cost was solved through the partnership between the public and private sector(Khan, 2005).

Resisting the change is considered the second major challenge because using technology in education and changing methods of teaching to access into the level of creativity requires the teacher to change his traditional way in teaching and following up new methods where the learner is the center of the educational process not the teacher.

This movement of change was a challenge to many of the teachers who used to use the ordinary system in addition to the teachers and the learners' lack of the knowledge of using the modern technologies as the computer and searching the international communication network. But the awareness and motivation policy which the ministry applied in implementing the steps of change led to the acceptance of the new system gradually and the signs of change started to appear according the area and the surrounding environment. 


\section{Problem of the Study \& Its Questions}

The problem of the study is seen by the big amount of money which the Ministry of Education spent on providing the schools with the computer labs, computerizing the curriculum and rehabilitating the teachers in order to activate using e-learning in the Jordanian schools for the advantages which this kind of learning has. But there is a shortage in the teacher use of e-learning system. This study assumes that there are many obstacles that hinder activating e-learning and it also assumes that there are differences in these obstacles regarding the differences of the variables of the study which are: sex, experience and the specialization. So this study tries to identify the obstacles facing e-learning from the perspective of the teachers of the secondary level by answering the following two questions:

i. What are the e-learning obstacles on the Ministry of Education in Jordan from the perspective of the teachers of the secondary level?

ii. Are there any statistically significant difference sat the level of significance $(a=0.05)$ attributed to the variable of the study: sex, specialization and the experience?

\section{Significance of the Study}

It is hoped that the results of this study will be useful for the educational leaders and decision makers in the Ministry of Education in Jordan through knowing the obstacles of using the system of e-learning and working hard to overcome these obstacles. And it is also hoped that this study helps in supplying the educational field with a new study about e-learning and the obstacles of applying it.

\section{Terms of the Study}

E -learning: using electronic means in learning as the computer and the educational software which are prepared and then used by the learner to help him understanding the scientific material with the help of the teacher and his guidance.

\section{Website of Ministry of Education}

It is the educational website which Ministry of Education designed and displayed via Internet to apply the e-learning (www.elearning.jo)

\section{Limitation of the Study}

This study is limited to a sample of the secondary schools' teachers in the Ministry of Education for the year 2011-2012 


\section{Previous Studies}

Drake (2000) shed a light on a number of obstacles of e-learning in the classroom showing that the computerized educational programs were designed and confirmed by the higher administrations and then the teachers were asked to apply them and most of the time these programs were resisted by the teachers because they did not meet their different needs. And obstacles as the teachers' lack of experience of using the computer in education before teaching and the lack of experience in the computerized educational programs during their service in teaching which made them have positive attitudes towards it.

And a study of Cuban, Kirkpatrick, and Peck(2001), which was applied on two school prepared with technology in California State, concluded that the availability of the computers and their accessories rarely lead to the great and effective use of technology by the teachers and the students. Data was collected using interviews with the teachers and the learners, class observations and revising the schools' documents the results of the study revealed that more than $70 \%$ of the teachers in these two school did not use technology in education because they did not have sufficient time and the limitation of the training courses presented to the teachers.

And a study of Woodbridge(2004) confirmed the previous results, the training which is provided to the teacher in using the computer is not sufficient and the teacher who can use the computer in education lack the experience in teaching using the computer. The teachers also do not have the technological knowledge and the number of the computers is not enough which some of them are old.

A study of Wanshaq (2005) showed that the most important obstacles that hinder using the computer in education are the decision makers' lack of convince of the technology importance in the Arabic educational systems in addition to the inappropriateness of the educational software and the shortage of the trained teachers. And the results of the study also showed that the female teachers realized the obstacles of e-learning more than the male teachers.

The study of Badrani(2005) aimed at knowing the degree of the availability and the use of the modern technological ways in the private school in Riyadh. And the results of the study revealed that the availability and the use of modern means of technology in education is low because of some obstacles which most of them related to the teacher as lack of physical incentives presented to the teachers, their big number of classes and lack of training presented to them.

The results of the study of Akbaba-Altun(2006) showed that the schools lack of the technological knowledge and the support they provided to activate using technology in education is poor. And the supervisors did not supervise the classes of information technology. All of these reasons formed obstacles of using technology in education.

The study of Mohammad \& Sheikh \& Ateia (2006) assured that the most significant obstacles of e-learning in the Hashemite University in Jordan is that the community is not aware of the importance and the advantages of this kind of learning, the number of the specialized in this 
field is few and the students did not respond for this new type of education because they used to use the traditional way in education.

The study of Carr(2007) investigated the views of the administrators and the teachers of elearning. The results of the study revealed that although there were many advantages of elearning, there were many obstacles that hinder its efficiency, some of them related to the learners' ability to interact with the e-learning programs and the teachers do not have the efficiency in teaching the materials (subjects) electronically.

And Asaf's study (2007) addressed the fields of using the computer in the class room teaching and its obstacles in the higher basic school. The results of the study showed that the teachers used the computers in preparing database of the students and in preparing the students' records of grades. And there were many obstacles that hinder their use of the computer in education as the big number of classes, insufficient number of the machines and their low quality.

Lee, Shen Tsai (2008) applied the e-learning in Taiwan's vocational schools. They designed three shapes of learning; learning via internet, self -learning and the learning that blended the two shapes and they studied these shapes' impact on the students. The results revealed positive attitudes towards learning via network and there is a number of difficulties facing elearning as difficulty of attracting the students to the lesson because of their knowledge of the games and shopping websites and other extractors that internet provides.

Alhomran \& Ajlouni( 2009) conducted a study to identify the real status of information technology and communications in some of the exploratory Jordanian schools. And the results revealed the ministry of education provides the modern machines, tools and the software and it supplies some teachers with laptops. Although of this, there are some obstacles that reduce employing information technology and communications in the class as the crowded classes, weakness of the network and the shortage of the students' experience in using the accessories of technology.

\section{Comment on the Previous Studies}

In light of the previous presentation of the studies which addressed e-learning, it is noticed that the most of the studies addressed the e-learning obstacles at schools from the teachers and the students' perspective and the most important obstacles were the weakness and low quality of the training programs presented to the teachers before and during the service at schools in the field of using the computer in education, and there were technical obstacles concerning the computer's labs, the tools used to collect data varied for example, questionnaire, interviews, observation and records' revision, and these studies were conducted in different environments for instance: European, Arabic or local. The Jordanian studies which discussed e-learning obstacles were few and the local studies did not address the technical and administrative obstacles which are related to the administration of the school as it considered a facilitator in activating using the computer. And the previous studies did not discuss some of the variables related to the teacher as sex, specialization and years of 
experience and their relation with the obstacles of using e-learning. So, this study came to shed a light on e-learning obstacles in the secondary school in Amman, the fifth Area. These obstacles were divided into field; the first one related to the teacher and the second one related to the technical and administrative aspects. And this study assumes that there is an impact of some variables concerning the teacher and their relation to the activation of using e-learning.

\section{Method and the Procedures}

It includes description of the methodology of the study, its population and sample and it includes a description to the procedures of the study and the statistical analysis which was used.

\subsection{Methodology of the Study}

To achieve the objectives of this study, the analytical descriptive approach was adopted

\subsection{Population of the Study and Its Sample}

The population of study consisted of all the secondary schools' teachers in the directorate of education of Amman( the fifth Area)for the scholastic year 2011-2012 and it includes school of Wadi Seair and Nau'r Districts and the number of the secondary schools was (50); 23 schools for male and 27 schools for female. The number of the teachers in who teach in these school was 816 from different scientific and humanistic specializations with a variety of practical experiences and all of them were BA holders. A random sample consisted of (201) out of the population of the study with (24\%). And table (1) illustrated the distribution of the sample of the study.

Table 1: Distribution of the Sample of the Study According the Variables of the Study

\begin{tabular}{llcc}
\hline \multicolumn{1}{c}{ Variable } & \multicolumn{1}{c}{ Categories } & repetition & proportion \\
\hline \multirow{2}{*}{ Sex } & Male & 85 & $\% 42,3$ \\
& Female & 116 & $\% 57,7$ \\
Scientific specialization & Scientific subjects & 81 & $\% 40,5$ \\
& Humanistic subjects & 120 & $\% 59,5$ \\
\multirow{2}{*}{ Educational experience } & Less than 5 & 37 & $\% 18,4$ \\
& 6-10 & 100 & $\% 50$ \\
Total & More than 11 & 64 & $\% 31,6$ \\
\hline
\end{tabular}

\subsection{Tool of the Study}

A questionnaire which consisted of 30 items was developed and it was divided equally on the two fields; obstacles regarding the teacher and technical and administrative obstacles.

\subsubsection{Validity \& Reliability}

To make sure of the tool's apparent and content validity, it was presented to a group of the 
arbitrators who are specialized in the field of this study and their comments and opinions were taken into account and some of the items were modified. Every item in the questionnaire was given a weight according to Likert scale and the means were considered respectively as follows: from 4.2 - 5 very high, from 3.4-4 high, from 2.6 - 3.3 moderate, from $1.8-2.5$ low and less than 1.8 very low. And to achieve the reliability of the tool, the element of the internal consistency of the items was calculated according Cronbakh Alpha where the total consistency of the questionnaire was $(0.083)$, the coefficient of internal consistency of the items according to Cronbach's alpha equation where the value of the overall of reliability of the questionnaire was $(0.83)$.

\subsubsection{Procedures of the Study}

After the tool of the study had been prepared, its stability and validity was confirmed and they were acceptable. About 210 questionnaires were distributed on the sample of the study which is consisted of all the teachers of the secondary schools of Wadi Seir and Nau'r districts in Amman fifth Area of the directorate of education in the academic year 2011-2012. Nine questionnaires were excluded because they did not meet the requirements.

\subsubsection{Variables of the Study}

First: the independent variables

1. Sex: has two level male and female.

2. Specialization : has two levels scientific \&humanistic

3. Experience :has three levels: 1-5 years , 6-10 years , more than 11

Second: dependent variables

1- E-learning obstacles from the perspective of the secondary level's teachers.

\section{Statistical Treatment}

To answer the questions of the study, means, standard deviations, $t$ test and ANOVA were used to reveal the differences according the variables of the study.

\section{Results \& Discussion}

To answer the first question: "What are the e-learning obstacles in the ministry of education from the secondary level's teachers' perspective? The means and standards deviations of the teachers' responses of the first and second fields and the tool a as a total were calculated, table (2) illustrated this: 
Table 2: Means and Standard Deviations of E-learning Obstacles from the Teachers' Perspective in the Fields of the Tool as Total Ascending

\begin{tabular}{clcccc}
\hline Field's order & \multicolumn{1}{c}{ Field } & Mean & Std & Field's rank & Degree \\
\hline 1 & $\begin{array}{l}\text { Technical and } \\
\text { administrative } \\
\text { obstacles }\end{array}$ & 3.17 & .30 & 1 & Moderate \\
2 & $\begin{array}{l}\text { Obstacles } \\
\text { related to the } \\
\text { teacher }\end{array}$ & 2.86 & .24 & 2 & Moderate \\
Total degree & & 3.01 & .27 & Moderate & \\
\hline
\end{tabular}

Table (2) showed that the administrative and technical obstacles came first with moderate degree with a mean (3.17) and std (0.30), while the obstacles regarding the teachers came second with moderate degree with a mean (2.86) and std (.24), and table (3) illustrated the means and the standard deviations of e-learning obstacles from the teacher' perspective in the fields of the technical and administrative obstacles ascending.

Table 3: The Means and the Standard Deviations of E-learning Obstacles from the Teacher' Perspective in the Fields of the Technical and Administrative Obstacles Ascending

\begin{tabular}{|c|c|c|c|}
\hline Item'sorder & Item & Mean & Std \\
\hline 25 & Big number of the students in one class hinder e-learning. & 4.81 & .52 \\
\hline 30 & The number of the computer labs in the school is little. & 4.81 & .52 \\
\hline 20 & Insufficient number of the computers in the labs & 4.77 & .52 \\
\hline 16 & $\begin{array}{l}\text { Absence of questioning by the school administration and the } \\
\text { supervisor. }\end{array}$ & 4.47 & .81 \\
\hline 19 & No connection with the e-learning websites & 4.00 & .65 \\
\hline 21 & The computers which are available are old and unprepared. & 3.83 & .91 \\
\hline 28 & $\begin{array}{l}\text { The computers labs are busy of the classes of the computer } \\
\text { subject at school. }\end{array}$ & 3.58 & .84 \\
\hline 18 & Big number of the students in one class hinder e-learning. & 3.54 & .78 \\
\hline 22 & $\begin{array}{l}\text { Internet is slow in opening and searching the pages of the } \\
\text { computerized curriculum. }\end{array}$ & 2.81 & .86 \\
\hline 27 & $\begin{array}{l}\text { Facing many technical problems within the computers during } \\
\text { application. }\end{array}$ & 2.42 & .87 \\
\hline 17 & $\begin{array}{l}\text { The repeated absence of the computer technician and the } \\
\text { closure of the lab. }\end{array}$ & 2.36 & .89 \\
\hline 23 & The administrative complications do not courage e-learning. & 2.11 & .75 \\
\hline 24 & There is computer technician at the school. & 2.00 & .73 \\
\hline 26 & $\begin{array}{l}\text { The computer technician is unable to treat the technical } \\
\text { problems that appeared. }\end{array}$ & 1.10 & .30 \\
\hline 29 & $\begin{array}{l}\text { The students' knowledge of the search skills via internet is } \\
\text { low. }\end{array}$ & 1.09 & .28 \\
\hline \multicolumn{2}{|c|}{ Total degree of the Field } & 3.17 & .30 \\
\hline
\end{tabular}


Table (3) showed that item (25): "the crowded classes hinder e-learning" and item(30): "lack number of computers labs in the same school" have got the highest mean (4.81) and standard deviation (.52)and with a very high degree. This result may due to the teachers' belief that it is difficult to control the students whose number exceeds 50 in the lab and their movement to the comport labs is difficult in addition to small size of the labs and the few number of the computers compared to the number of the students. And computerizing and e-learning covered all the curricula in addition to the computer subject and both need a sufficient number of labs and computers and most of the secondary school have no more than two computer labs and mainly there are problems in the school because of the procedures of preserving the lab to implement the computerized curriculum or the computer classes. so these two obstacles are considered as the most significant obstacles of e-learning. And this result agrees with the result of the study of Woodbridge(2004) which considered the insufficient number of the computers increases the problem of e-learning. And this result differed with the study of Cuban.et al(2001) which showed the that the availability and the preparation of the computers' labs does not necessarily leads to the activation of using technology in education.

And item(26): " the students lack of the skills of using the computers" and item(29): "“" the students lack of the skills of searching via internet" got the least mean (1.09) and standard deviation (0.28) with a low degree. And this result may be attributed to the students' experience in using the computer and searching via internet, having comports connected to internet at their houses and their realization to the importance of the computer and internet in education and in other issues as enjoyment. So these items are not considered obstacle of elearning. This result agreed with study of Lee et al(2008)which considered the students' awareness of using the computer and internet a reason of their distraction during the process of e-learning.

Table 4: Means and Standard Deviations of E-learning Obstacles from The Teachers' Perspective of the Field of Obstacles Related to The Teacher Ascending

\begin{tabular}{clrrrr}
\hline $\begin{array}{c}\text { Item } \\
\text { order }\end{array}$ & \multicolumn{1}{c}{ Item } & Mean & Std & Degree \\
\hline 7 & $\begin{array}{l}\text { The crowded classes hinder using e-learning. } \\
1\end{array}$ & $\begin{array}{l}\text { The number of the teacher's classes is high. } \\
4\end{array}$ & 4.95 & .29 & IVery high \\
Many clerical burden which the teacher have to & 4.46 & .56 & Very high \\
10 & $\begin{array}{l}\text { There are no training courses to activate e-learning } \\
\text { and following it up. }\end{array}$ & 4.05 & .82 & High \\
3 & $\begin{array}{l}\text { The teachers prefer the traditional methods in } \\
\text { teaching rather using the computer and internet. }\end{array}$ & 4.05 & .72 & High \\
5 & $\begin{array}{l}\text { It is difficult to manage the e-learning class. } \\
14\end{array} \quad \begin{array}{l}\text { The difficulty to reveal the weak and strong points of } \\
\text { the students in the e-learning. }\end{array}$ & 2.90 & .83 & Moderate \\
12 & $\begin{array}{l}\text { The difficulty to follow up individually the students } \\
\text { during e-learning. }\end{array}$ & 2.36 & .89 & Low \\
11 & The teachers do not know much about the & 2.10 & .60 & Low \\
\hline
\end{tabular}




\begin{tabular}{|c|c|c|c|c|}
\hline 13 & $\begin{array}{l}\text { e-learning requires high skills which the teacher does } \\
\text { not have. }\end{array}$ & 2.08 & .89 & Low \\
\hline 15 & $\begin{array}{l}\text { e-learning does not into account the individual } \\
\text { differences between the students. }\end{array}$ & 2.01 & .97 & Low \\
\hline 9 & The colleagues do not support e-learning. & 2.00 & .68 & Low \\
\hline 8 & $\begin{array}{l}\text { absence of the humanistic relation between the } \\
\text { teacher and the learner in the e-learning.. }\end{array}$ & 1.95 & .69 & Low \\
\hline 11 & $\begin{array}{l}\text { Teachers' lack of having the skills of using the } \\
\text { computer and internet. }\end{array}$ & 1.57 & 1.09 & Very low \\
\hline 6 & Low trust of the efficiency of e-learning & 1.26 & .67 & Very low \\
\hline \multicolumn{2}{|c|}{ Total of the Field } & 2.86 & .24 & Moderate \\
\hline
\end{tabular}

Table (4) showed that item (7): "crowded curriculum hinder using e-learning", and the item(1): "the teachers' big number of classes" have got the highest mean (4.95) with a standard deviation (0.29) and their degree was very high. And this result is logical and consistent with the attitudes of Ministry of Education which have been started recently in the curriculum especially the secondary one. And e-learning requires from the teacher previous preparation and cooperation with the school administration and the supervisors of the computer labs. To have computer lab on time and to coordinate these issues, there is a need for time and effort so if the teacher has big number of classes, he will not have sufficient time to do these tasks. Therefore, these two items got the highest mean. And this result agreed with the results of the study of Homran \& Ajlouni(2009), the study of Asaf(2007), study of Cuban, et al (2001) and the study of Badrani(2005) that the teacher's big number of classes is the most important obstacle of e-learning .

And item(6): " the low trust of the efficiency of e-learning" got the lowest mean (1.26) with standard deviation (0.67). This result confirmed the teacher's awareness of the importance of e-learning, their ability for adaptation with this kind of education after they realised its benefits in presenting the process of teaching in an excited and entertaining method so this item was not considered an obstacle for e-learning. And this result differed with what the study of (Mohammad,Sheikh\&Ateia,2006) has concluded which assured that the most important obstacle of e-learning is the individuals' lack of awareness of this kind of education and its advantages.

And to answer the second question: "Are there significant difference at te level of significance $(\mathrm{a}=0.05)$ attributed to the sex, specialization and the experiences' variables ?

The means and the standard deviations were calculated. And (T) test for the independent samples to reveal the differences regarding sex, experience and experience variables and ANOVA test was used to the years of experience variable 
First: sex variable

Table 5: Results of (T) Test to Examine the Differences in the E-Learning Obstacles from the Teachers' Perspective According the Sex Variable

\begin{tabular}{|c|c|c|c|c|c|c|c|}
\hline Field & Sex & $\mathrm{N}$ & Mean & Std & T value & d.f & Siq \\
\hline \multirow{2}{*}{$\begin{array}{l}\text { Technical } \\
\text { administrative } \\
\text { obstacles }\end{array}$} & \multirow{2}{*}{$\begin{array}{l}\text { Males } \\
\text { females }\end{array}$} & 85 & 3.12 & .20 & \multirow[b]{2}{*}{-2.30} & \multirow[b]{2}{*}{199} & \multirow[b]{2}{*}{.02} \\
\hline & & 116 & 3.22 & .36 & & & \\
\hline \multirow{2}{*}{$\begin{array}{l}\text { Obstacles related to } \\
\text { the teacher }\end{array}$} & Males & 85 & 2.88 & .23 & \multirow{2}{*}{1.19} & \multirow{2}{*}{199} & \multirow{2}{*}{.23} \\
\hline & Females & 116 & 2.84 & .24 & & & \\
\hline
\end{tabular}

Table (5) showed that there are statistically significant differences at the level of significance of the obstacles of e-learning from the teachers' perspective in the field of the technical and administrative obstacles attributed to the sex variable in favour of the females. And this result may due to the fact that the e-learning problems represented by the items of this field are clearer at the females' schools. The female teachers' feeling of the technical and administrative obstacles is higher than males'. And this result agreed with the study of Wanshiq Qamar(2005) that concluded the female teachers were more aware of the obstacles of e-learning. And the table illustrates that there were no statistically significant differences related to the sex variable in the other obstacles related to the teacher and this may due to the lack of differences between the teachers in their educational levels, experiences, training so the mental and cognitive levels are the same for both sexes.

\section{Second: specialization}

Table 6: Results of (T) Test to Examine the Differences in the E-learning Obstacles from The Teachers' Perspective According the Specialization Variable

\begin{tabular}{|c|c|c|c|c|c|c|c|}
\hline Field & Specialization & $\mathrm{N}$ & Mean & Std & T value & d.f & Sig. \\
\hline \multirow{2}{*}{$\begin{array}{l}\text { Technical and } \\
\text { administrative } \\
\text { obstacles }\end{array}$} & Scientific & 81 & 3.11 & .20 & \multirow[b]{2}{*}{-2.42} & \multirow[b]{2}{*}{199} & \multirow[b]{2}{*}{.01} \\
\hline & Humanistic & 120 & 3.22 & .35 & & & \\
\hline \multirow[t]{2}{*}{$\begin{array}{l}\text { Obstacles related } \\
\text { to the teacher }\end{array}$} & Scientific & 81 & 2.86 & .22 & \multirow[t]{2}{*}{.21} & \multirow[t]{2}{*}{199} & \multirow[t]{2}{*}{.83} \\
\hline & Humanistic & 120 & 2.86 & .25 & & & \\
\hline
\end{tabular}

Table (6) showed that there are statistically significant differences at the level of significance $(a=0.05)$ in e-learning obstacles from the teachers' perspective in the field of technical and administrative obstacles attributed to the specialization variable in favor of the human subject' teachers and this may due to the fact that the teachers of human sciences employed technology in education more than the teachers of scientific subjects for many reasons as : a big number of classes is allocated to the human subjects more than to scientific subjects and the teachers of scientific subjects depend more on the scientific labs and experiments. So the teachers of human sciences are more aware of the technical and administrative obstacles of e-learning than others. While there are no statistically significant differences at the level of significance in the fields of the obstacles related to the teacher. The obstacles of this field are 
the same for all the teachers no matter what their subject of teaching is because their experiences and qualifications are the same and even they joined the same training courses.

\section{Third: experience variable:}

Table 7: Means and standard deviations of e-learning obstacles from the teachers' perspective in light of experience variable

\begin{tabular}{lclcc}
\hline Field & Experience & $\mathrm{N}$ & Mean & Std. deviation \\
\hline \multirow{2}{*}{ Technical and } & $1-5$ & 37 & 3.10 & .16 \\
administrative & $6-10$ & 100 & 3.19 & .25 \\
obstacles & More than 11 & 64 & 3.18 & .42 \\
& Total & 201 & 3.17 & .30 \\
Obstacles & $1-5$ & 37 & 2.94 & .26 \\
regarding the & $6-10$ & 100 & 2.85 & .20 \\
teacher & More than 11 & 64 & 2083 & .28 \\
& Total & 201 & 2.86 & .24 \\
\hline
\end{tabular}

Table (7) showed that there are apparent difference between the means of the sample's responses according the experience variable and to know if these differences are statistically significance, ANOVA was used and table (8) illustrates this:

Table 8: Results of ANOVA test's analysis of the means of e-learning obstacles from the teachers' perspective in light of the experience variable

\begin{tabular}{lcccccc}
\hline Field & $\begin{array}{c}\text { Source of } \\
\text { variety }\end{array}$ & Total of Seq & DF & $\begin{array}{c}\text { Mean } \\
\text { squares }\end{array}$ & F & Sig. \\
\hline $\begin{array}{l}\text { Technical and } \\
\text { administrative } \\
\text { obstacles . }\end{array}$ & $\begin{array}{c}\text { Between } \\
\text { groups }\end{array}$ & .23 & 2 & .11 & 1.21 & .29 \\
& $\begin{array}{c}\text { Within groups } \\
\text { Total }\end{array}$ & 18.94 & 198 & .09 & & \\
Obstacles & $\begin{array}{c}\text { Between } \\
\text { groups }\end{array}$ & .27 & 2 & .138 & 2.37 & .96 \\
related to the & $\begin{array}{c}\text { Within groups } \\
\text { teacher }\end{array}$ & 11.52 & 198 & .05 & & \\
& Total & 11.80 & 200 & & & \\
\hline
\end{tabular}

It is clear from table (8) that the apparent differences between the means are not statistically significant at the level of significance $(a=0.05)$, which means that there is no significance impact to the experience variable. And this may due to the fact that the teachers with different experiences are BA holders, and they have experience in using the computer, and they received training to activate, and employ the computer and internet in education through joining the ICDL and INTEL courses, which both aimed to employ technology in education. So the teachers' responses did not vary, although of their variance in the educational experiences as well as their feeling of e-learning obstacles did not change. 


\section{Recommendations}

1. Overcoming the obstacles, which this study and other studies showed that they hinder e-learning.

2. Conducting further studies that discussed obstacles of e-learning from the perspective of other categories as supervisors and parents.

3. Working on developing the infrastructure that supports using e-learning as providing computer labs, computers, internetwork that suit the number of the students at the school.

\section{References}

Akbaba-Altun, S. (2006). Complexity of Integrating Computer technology into Education in Turkey. Educational Technology \&Society, 9(1), 176-187.

Anderson, T, \& Elloumi, F. (2004). Theory and Practice of Online Learning. Printed at Athabasca University.

Asaf, Hamza. (2007). Investigating areas of using the computer in class teaching and its obstacles. Unpublished thesis, University of Jordan: Jordan.

Azmi, Nabeil. (2008). Technology of E-Learning. Dar Fikr Arabi.

Badrani, Mohammad. (2005). The extent of availability and use of modern means of technology in the schools of private education from the perspective of the teachers of the moderate level. Unpublished thesis, University of Jordan, Jordan.

Bosman, K (2002). Simulation-based E-Learning Syracuse. University Educational Technology, 29-31.

Carr, H. (2007). Administrator and Teacher perception of the advantages of online coerces. Educational Technology, 27(8), 29-31.

Cuban, L., Kirkpatrick, H., \& Peck, G. (2001). High Access and Low use of technology in high school classrooms; Explaining an apparent paradox. American Educational Research Journal, 38(4), 813-834. http://dx.doi.org/10.3102/00028312038004813

Drake, S. (2000). Problems with Technology integration. Retrieved from http://nmsu.edu/educ621/scott3.htm

Fayumi, Nabeil. (2004). E-Learning in Jordan: A strategic Choice to achieve the National Vision, the challenges, the achievements. Regional Forum of Information Technology and Communication of e-learning. International Telecommunications Union, Damascus.

Harris, J., Mishra, D., \& Koehler, M. (2009). Teachers Technological Content Knowledge and Learning Activity Types: Curriculum-based Technology. International Society for Technology in Education, 41(4), 393-416. 
Homran, Mohammad \& Ajloni, Khaled. (2009). A survey study to the status of information technology and communications in the exploratory schools in Jordan. Journal of Association of Arab Universities, College of Education, University of Damascus, 2(7), 53-72.

Khan, B. (2005). Web-based training. New Jersey: Educational Technology publication.

Khan, Badr. (2005). Strategy of e-learning, a case study of College of human and social sciences. University of UAE, UAE Center of studies and researches: Abu Dhabi.

Lee, T., Sheen, P., \& Tsai. C. (2008). Applying web-Enabled problem Based Learning and self Regulated Learning to Add Value to Computing Education in Taiwan's Vocational Schools. Educational Technology \& Society, 11(3), 13-25.

Mheisn, Abdallah \& Mobarak, Ahmad. (2005). E-Learning: Luxury or Necessity, A paper presented to the forum of Mostagbel School, King Saud University, Riyadh.

Ministry of Education. (2012). Directorate of Training and Rehabilitation's Plan. Ministry of Education, Amman, Jordan.

Ministry of Education. (2004). Executive Summary of the project of educational development towards Knowledge Economy. Managing Directorate of Development \&Educational Research. Amman: Jordan.

Mohammad, Gebreil, Asem, Sheikh \& Anas, Ateia. (2006). Obstacles of using e-learning from the perspective of the students of Hashemite University. Journal of educational and psychological Sciences, 4, 185-205.

Mosa, Abdallah \& Mobarak, Ahmad. (2005). E-Learning: Basics \& Applications. Shabaka Al-bayanat Foundation. Riyadh, Saudi

Rashed, Fares Ibrahim (2003). E-learning :reality \&Ambition. The $1^{\text {st }}$ international forum of e-learning at the schools of King Faisal in Riyadh from 21-23 April.

Salem, Ahmad. (2006). Means of information technology(ed2.). Riyadh :Dar Roshd.

Talba, Mohammad. (2007). E-Learning towards Developing Education Strategy in Jordan in the 21c. Arab Network For Open And Distance Learning. Amman, Jordan, National Library.

Turkey, Saleh. (2003). E-Learning: importance and benefits. The $1^{\text {st }}$ international forum of elearning at the schools of King Faisal in Riyadh from21-23 April.

Wanshaq Alqamar (2005). Why did the studies fail in providing a comprehensive presentation for the technology used in the Learning Process. Retrieved from www.almdares.net/modules

Woodbridge, J. (2004). Technology Integration as a Transforming Teaching Strategy. Retrieved from www.techlearning.com

Zajda, J., \& Gibbs, D. (2009). Comparative Information Technology: E-learning in Schools: 
Making Successful Connections. Springer Science Media.

\section{Copyright Disclaimer}

Copyright reserved by the author(s).

This article is an open-access article distributed under the terms and conditions of the Creative Commons Attribution license (http://creativecommons.org/licenses/by/3.0/). 